\title{
Risk of malnutrition and associated factors in institutionalized elderly persons
}

Abstract

Objective: to evaluate the risk of malnutrition and associated factors in institutionalized elderly persons. Method: a cross-sectional study was carried out with elderly persons living in long-term care facilities in the municipal regions of Passo Fundo (Rio Grande do Sul) and Carazinho (Rio Grande do Sul) in 2017. A standardized, pre-codified questionnaire with sociodemographic variables was used, along with anthropometric data and the Mini Nutritional Assessment. Cognitive decline and non-intentional weight loss were also evaluated. The qualitative variables were presented in terms of univariate frequencies and the quantitative variables were described through measures of central tendency and dispersion. In order to verify the association between the categorical variables, the Pearson's correlation coefficient, Chi-Squared test and the Fisher Exact test were applied, and in the crude and adjusted analysis the Poisson regression was used with robust variance. The level of significance was 5\%. Results: a total of 399 elderly people were included, of whom $69.9 \%$ were female, $54.5 \%$ were aged 80 years or older and $88.4 \%$ were white. Of these elderly people, $61.7 \%$ lived in non-profit facilities. In the evaluation of nutritional status, $26.6 \%$ of the elderly were found to be malnourished, $48.1 \%$ were at risk of malnutrition and $25.3 \%$ had normal nutritional status. The highest prevalence ratio of at risk of malnutrition/malnutrition was with cognitive decline and unintentional weight loss $(p<0.001)$. Conclusion: through the results, identifying nutritional status and the characteristics associated with the risk of malnutrition contribute to effective evaluation and nutritional monitoring, assisting in the prevention of diseases related to this condition.

\footnotetext{
Universidade de Passo Fundo, Faculdade de Educação Física e Fisioterapia, Programa de Pós-graduação em Envelhecimento Humano. Passo Fundo, Rio Grande do Sul, Brasil.

2 Universidade de Passo Fundo, Instituto de Ciências Biológicas, Departamento de Enfermagem. Passo Fundo, Rio Grande do Sul, Brasil.

3 Universidade de Passo Fundo, Instituto de Ciências Biológicas, Departamento de Nutrição. Passo Fundo, Rio Grande do Sul, Brasil.
}

\author{
Cássia Cassol Damo' \\ Marlene Doring ${ }^{2}$ \\ Ana Luisa Sant'Anna Alves ${ }^{3}$ \\ Marilene Rodrigues Portella ${ }^{2}$
}

Keywords: Nutritional

Status. Elderly. Homes for the

Aged. Manutrition. Aging. 


\section{INTRODUCTION}

Global malnutrition is considered one of the most common problems among the elderly population, and may interfere significantly with the evolution of the health of such individuals. Protein-caloric malnutrition contributes to increased mortality and susceptibility to infections and reduced quality of life, and can cause even greater problems among people living in long-term care facilities for the elderly (LTCF) ${ }^{1}$.

The characteristics of institutionalization make this population more vulnerable to impaired nutritional status. The numbers show that, in the majority of cases, a large part of the population is at risk of malnutrition, with a prevalence of more than $60 \%$ of the elderly having a deteriorated nutritional status $^{2,3}$.

The aging process brings with it physiological changes, such as alterations in taste, digestive disorders, polypharmacy, a reduction in lean mass and an increase in fat mass which contribute to a nutritional state of malnutrition. Allied to this, environmental conditions including an inadequate diet and lifestyle make the elderly even more susceptible $^{4}$. In the elderly living in LTCF, the presence of depression, cognitive and functional impairment and difficulty in swallowing often increase the possibility of malnutrition, with mortality the main result ${ }^{5}$.

These aspects show, therefore, the vulnerability of elderly persons residing in LTCF to nutritional risk, suggesting a need for the early and systematic implementation of nutritional evaluation and actions aimed at prevention. Different methods of nutritional evaluation can provide support for health professionals in the monitoring of nutritional risks and, thus, guide the application of resources for nutritional care aimed at promoting the quality of life and autonomy of this population. In light of the above, the present study aims to evaluate the risk of malnutrition and associated factors in institutionalized elderly persons.

\section{METHOD}

A cross-sectional study of elderly persons living in LTCF in Passo Fundo and Carazinho - Rio Grande do Sul (RS) - was carried out in 2017. This is a section of the "Patterns of Aging and Longevity: biological, educational and psychosocial aspects" survey, carried out by the Graduate Program in Human Aging of the Universidade de Passo Fundo (UPF).

We included 15 LTCF from the municipal regions of Passo Fundo and Carazinho (RS). All elderly residents were surveyed, based on the following inclusion criteria: age 60 years or more, of both genders, for whom nutritional status could be assessed. The exclusion criteria were: impossibility of carrying out anthropometric evaluation and answering the questions of the questionnaire. It was decided to include elderly people living in LTCF in the two municipal regions in the study as they presented similarities in the general population in terms of the proportion of elderly persons, distribution by gender and age group.

The municipality of Passo Fundo is located to the north of the state of Rio Grande do Sul and its population is estimated at 196,741 inhabitants, of whom 26,729 are elderly and aged 60 years or more, corresponding, therefore, to $13.5 \%$ of the population total. The municipality of Carazinho is also located to the north of the state and has a population of 62,037 inhabitants. Of these, 10,007 thousand are elderly and aged 60 or over, corresponding to $16.1 \%$ of the population ${ }^{6}$.

For a prevalence of outcome (prevalence of nutritional risk in the institutionalized elderly) of $20 \%$ the following data were considered for the sample calculation: a ratio of non-exposed: exposed of 1:2, a 95\% confidence level and 80\% statistical power, giving a total of 209 elderly persons. However, all the elderly individuals who fulfilled the inclusion criteria were included, as the sample calculation of the original study included other outcomes of interest of a larger sample size. 
Data collection was carried out in the LTCF by the research team. The interviewers included professors/researchers, masters students, students from the area of health and recipients of scientific initiation grants, all of whom underwent training.

A standardized, pre-codified questionnaire was used. The variables were: sociodemographic (type of LTCF, age, gender, skin colour), anthropometric [weight, height, Body Mass Index (BMI)], Mini Nutritional Assessment (MNA), cognitive decline evaluated by the Mini Mental State Exam ${ }^{7}$ through questions related to arithmetic, memory and orientation, and self-reported non-intentional weight loss in the previous 12 months.

The outcome was evaluated using the MNA which is composed of six questions that include data on the reduction of food intake, weight loss in the previous three months, mobility, psychological stress or severe disease in the previous three months, neuropsychological problems and BMI. The scores were added together to give a total of between 0 and 14 points and classified according to the following cut-off points: 0 to 7 "malnutrition", 8 to 11 "at risk of malnutrition" and 12 to 14 "normal nutritional state".

Where it was impossible to weigh and measure the height of the elderly the measurements were estimated. Height was estimated using the equation of Chumlea et al. ${ }^{9}$, based on gender and using age and knee height $(\mathrm{KH})$. Weight was also estimated using the Chumlea et al. ${ }^{9}$ equation, based on gender and using calf circumference (CC), KH, arm circumference (AC) and subscapular skinfold (SS). All the anthropometric measurements followed the protocols established by the International Society for the Advancement of Kinanthropometry (ISAK) ${ }^{10}$.

After being reviewed and codified, the questionnaires were entered in a statistical software package. The qualitative variables were presented as univariate frequencies (absolute and relative). The quantitative variables were described by measures of central tendency and dispersion. To verify the association between the categorical variables, the Chi-squared test, Pearson's Correlation Coefficient and Fisher's Exact were used, and Poisson Regression with robust variance was used in the crude and adjusted analysis. The level of significance was 5\%.

The study was approved by the Research Ethics Committee of UPF under approval number 2,097,278. All the elderly were protected by signing a Free and Informed Consent Form. The study followed the standards of Resolutions $n^{\circ} 466 / 2012$ and $n^{\circ}$ 510/2016 which deals with research involving human beings.

\section{RESULTS}

A total of 399 elderly people were evaluated, $69.9 \%$ of whom were female, $54.5 \%$ were aged 80 years or older and $45.5 \%$ were less long-lived, $88.4 \%$ were white and $11.6 \%$ were non-white. Of these elderly people, $38.3 \%$ were residents of private institutions and $61.7 \%$ of non-profit institutions.

In the evaluation of nutritional status according to the MNA, $26.6 \%$ of the elderly were malnourished, $48.1 \%$ were at risk of malnutrition and $25.3 \%$ had a normal nutritional status. The mean MNA score was 9.25 ( \pm 2.93$)$.

Table 1 presents the gross analysis between nutritional status according to the MNA (normal versus at risk of malnutrition/malnutrition) and socio-demographic variables, cognitive decline and unintentional weight loss. The highest prevalence of at risk of malnutrition/malnutrition was among the elderly living in private facilities, those who were long-lived, female and white. However there was no significant association between the variables. A higher prevalence of at risk of malnutrition/ malnutrition was identified among the elderly with cognitive decline and unintentional weight loss $(p<0.001)$.

In the adjusted analysis, we chose to include all the sociodemographic variables as well as the variables with a value of $p \leq 0.20$. Table 2 shows that the highest prevalence ratio of nutritional status of at risk of malnutrition/malnutrition remained among the elderly with cognitive decline and unintentional weight loss $(p<0,001)$. 
Table 1. Nutritional status of institutionalized elderly according to exposure variables (crude analysis). Passo Fundo, RS, 2018 (N=399).

\begin{tabular}{|c|c|c|c|c|c|c|c|}
\hline \multirow[t]{3}{*}{ Variables } & \multicolumn{4}{|c|}{ Nutritional State } & \multirow{2}{*}{\multicolumn{3}{|c|}{ Gross analysis }} \\
\hline & \multicolumn{2}{|c|}{ Normal } & \multicolumn{2}{|c|}{ At risk/malnutrition } & & & \\
\hline & $\mathrm{n}$ & $\%$ & $\mathrm{n}$ & $\%$ & PR & CI95\% & $p$-value \\
\hline \multicolumn{8}{|l|}{ Type of LTCF* } \\
\hline Private & 38 & 24.8 & 115 & 75.2 & 1.004 & $0.955-1.056$ & 0.862 \\
\hline Non-profit & 63 & 25.6 & 183 & 74.4 & 1 & & \\
\hline \multicolumn{8}{|l|}{ Longevity } \\
\hline Long-lived & 52 & 24.0 & 165 & 76.0 & 1.018 & $0.969-1.070$ & 0.480 \\
\hline Not long-lived & 49 & 27.1 & 132 & 72.9 & 1 & & \\
\hline \multicolumn{8}{|l|}{ Gender } \\
\hline Male & 32 & 26.7 & 88 & 73.3 & 0.989 & $0.937-1.044$ & 0.687 \\
\hline Female & 69 & 24.7 & 210 & 75.3 & 1 & & \\
\hline \multicolumn{8}{|l|}{ Skin colour } \\
\hline White & 87 & 24.9 & 262 & 75.1 & 1.032 & $0.957-1.121$ & 0.448 \\
\hline Non-white & 14 & 30.4 & 32 & 69.6 & 1 & & \\
\hline \multicolumn{8}{|c|}{ Cognitive decline } \\
\hline Yes & 52 & 18.7 & 223 & 81.3 & 1.149 & $1.080-1.223$ & $<0.001$ \\
\hline No & 49 & 42.2 & 67 & 57.8 & 1 & & \\
\hline \multicolumn{8}{|c|}{ Unintentional weight loss } \\
\hline Yes & 17 & 14.5 & 100 & 85.5 & 1.102 & $1.048-1.158$ & $<0.001$ \\
\hline No & 71 & 31.7 & 153 & 68.3 & 1 & & \\
\hline
\end{tabular}

*Long Term Care Facility for the Elderly

Table 2. Nutritional state of institutionalized elderly persons according to exposure variables (adjusted analysis). Passo Fundo, RS, 2018 (N=399).

\begin{tabular}{|c|c|c|c|}
\hline \multirow[t]{2}{*}{ Variables } & \multicolumn{3}{|c|}{ Adjusted analysis } \\
\hline & PR & $\mathrm{CI} 95 \%$ & $p$-value \\
\hline \multicolumn{4}{|l|}{ Type of LTCF* } \\
\hline Private & 1.018 & $0.900-1.151$ & 0.776 \\
\hline Non-profit & 1 & & \\
\hline \multicolumn{4}{|l|}{ Longevity } \\
\hline Long-lived & 1.013 & $0.889-1.154$ & 0.848 \\
\hline Not long-lived & 1 & & \\
\hline \multicolumn{4}{|l|}{ Gender } \\
\hline Male & 1.045 & $0.908-1.203$ & 0.539 \\
\hline Female & 1 & & \\
\hline \multicolumn{4}{|l|}{ Skin colour } \\
\hline White & 1.152 & $0.904-1.467$ & 0.253 \\
\hline Non-white & 1 & & \\
\hline \multicolumn{4}{|c|}{ Cognitive decline } \\
\hline Yes & 1.406 & $1.189-1.664$ & 0.000 \\
\hline No & 1 & & \\
\hline \multicolumn{4}{|c|}{ Unintentional weight loss } \\
\hline Yes & 1.228 & $1.092-1.380$ & 0.001 \\
\hline No & 1 & & \\
\hline
\end{tabular}

*Long Term Care Facility For The Elderly 


\section{DISCUSSION}

The present study showed that the majority of the studied population is at risk of malnutrition (48.1\%) or is already in a state of malnutrition (26.6\%). This result is common among the elderly, particularly those who reside in LTCF. The rate of nutritional risk in these environments can be as high as $95 \%$ of individuals ${ }^{11}$.

Studies that use the MNA to assess the nutritional status of institutionalized elderly persons are common in literature. Generally, the prevalence of individuals with impaired nutritional status exceeds those with good nutritional status. Vandewoude and Van Gossum ${ }^{12}$ conducted a survey in Belgium addressing institutionalized elderly persons and those residing in the community and found that the overall risk of malnutrition was $57 \%$, and was significantly higher among institutionalized persons $(p<0.001)$.

Corroborating this information, Senior et al. ${ }^{3}$, in a study carried out in Australia, found that $14.9 \%$ of the total institutionalized elderly were malnourished, $48.5 \%$ were at risk of malnutrition and $36.6 \%$ had a normal nutritional status. The results of a study by Souza et al. ${ }^{13}$ carried out in Uberlândia (Minas Gerais) also agree with those of the present study. This study evaluated a group of institutionalized elderly individuals and found the majority were malnourished or at nutritional risk, with rates of $26.2 \%$ and $41.6 \%$, respectively.

Diverging from the present study, a survey by Saka et al. ${ }^{14}$ conducted in Turkey with elderly residents of institutions showed that only $18.7 \%$ of the subjects were malnourished, $24.8 \%$ were at risk of malnutrition and $56.5 \%$ were well-nourished. Furthermore, a study by Serrano-Urrea and GarcíaMeseguer ${ }^{15}$ in Spain showed that $2.8 \%$ of the residents were malnourished, 37.3\% were at risk of malnutrition and $59.9 \%$ had normal nutritional status. Cultural characteristics, public policies and the economic development of these countries can be decisive for a positive outcome in the process of human aging. However, although the majority of the elderly have a good nutritional status, the prevalence of malnutrition/malnutrition risk is notable.

No significant association was found with the sociodemographic variables, however, it was observed that elderly people living in private institutions, who were long-lived, female and white had a higher prevalence of risk of malnutrition. It has been observed in literature, however, that some demographic conditions predispose the individual to an increased chance of developing malnutrition.

Old age brings changes in body composition, with malnutrition rates increasing as age increases. Vandewoude and Van Gossum ${ }^{12}$, in their research with community-aged and institutionalized adults, found that the risk of malnutrition was more frequent in the older age group $(p<0.001)$. In addition, the frequency of this condition was higher among women $(p<0.001)$. Stange et al. ${ }^{16}$, when evaluating elderly residents of institutions, also observed that those at nutritional risk were more often women $(p<0.05)$.

Diverging from the present study, Pereira et al. ${ }^{2}$ in a survey of elderly residents of institutions found that nutritional risk was more prevalent among men $(p=0.012)$. Another finding of this study is that individuals with low schooling had higher rates of nutritional risk $(p=0.042)$.

In relation to cognitive decline, this condition directly interferes with mealtimes, as sufferers for the most part present difficulties and dependence in the act of feeding themselves. It was observed in the present study that of the population in this condition, $81.3 \%$ are at nutritional risk. The numbers show that elderly people with cognitive decline have a 1.4 times greater prevalence of nutritional risk. The adjusted analysis showed that this condition was significantly associated with a condition of malnutrition/risk of malnutrition.

Literature supports the fact that elderly people with neurological problems are more likely to develop malnutrition. De Rouvray et al. ${ }^{17}$, in a study with elderly persons with and without dementia observed that patients with dementia were more malnourished than those without dementia $(p<0.001)$ possibly due to low food intake and being isolated during meals.

Likewise, data from the study by Pereira et al. ${ }^{2}$ with elderly people living in LTCF show that the prevalence of nutritional risk was higher among those with cognitive decline $(p=0.006)$. Carlsson et al. ${ }^{18}$ in a study with elderly individuals with physical and cognitive deficits, also noticed that 
the condition of nutritional risk was higher among individuals with cognition problems $(p=0.024)$. This condition was also higher among eating-dependent individuals $(p=0.014)$.

Vandewoude and Van Gossum ${ }^{12}$ also found in their research with community dwelling and institutionalized individuals that the risk of malnutrition was significantly higher among those with neuropsychological problems, including dementia or depression $(p<0.001)$. Furthermore, this condition was higher among elderly individuals with swallowing difficulties, mobility problems and social isolation $(p<0.001)$.

Also directly related to the nutritional status of the elderly, unintentional weight loss is common in the institutionalized population, and may be related to low food intake, which the data show to be a common event. The present study shows that among those interviewed with this condition, $85.5 \%$ were at nutritional risk, and elderly people with unintentional weight loss had a 1.2 times higher prevalence of nutritional risk. After adjusted analysis, we identified that this condition also remained significantly associated with a condition of risk of malnutrition/malnutrition.

Corroborating the present study, Rambousková et al. ${ }^{19}$, in a study of elderly residents of an LTCF, found that malnutrition was positively correlated with weight loss in the previous 3 months $(\mathrm{r}=0.45, p<0.001)$. There was also a positive correlation between MNA and BMI $(\mathrm{r}=0.57, p<0.001)$, immobility $(\mathrm{r}=0.63$, $p<0.001)$, arm circumference $(\mathrm{r}=0.56, p<0.001)$, and calf circumference $(\mathrm{r}=0.28, p<0.001)$.

As the data above support, the rates of institutionalized elderly at nutritional risk are high. The living conditions of these elderly people, including eating conditions and the presence of diseases, are closely related to the nutritional outcome. A consequence of a compromised nutritional status is a reduction in quality of life and a higher probability of mortality. Studies confirm this hypothesis by associating MNA scores with mortality, where a significant association was observed, that is, nutritional risk contributed to higher mortality (malnutrition: $28.0 \%$, nutritional risk: $20.0 \%$, normal: $10.6 \%, p<0.001)$. The importance of nutritional assessment with early detection of nutritional deficit among this population is therefore emphasized.

The results found in the present study are determinant for the remodeling of the nutritional care of institutionalized elderly persons and are in agreement with literature. However, interpretations should be made with caution, as this is a cross-sectional study, with the possibility of reverse causality and memory bias as the variables investigated occurred in the past.

\section{CONCLUSION}

The majority of the elderly persons were at risk of malnutrition and malnutrition (74.7\%), and the highest prevalence rate was among those with cognitive decline and unintentional weight loss. From these results it can be seen that identifying nutritional status and the characteristics associated with the risk of malnutrition contribute to the understanding of this phenomenon and the proper nutritional assessment and monitoring with early detection of individuals at risk of malnutrition, and the treatment of those who are already malnourished. Such measures can mean the prevention of diseases related to this condition and improvement in quality of life.

\section{REFERENCES}

1. Oliveira LP, Cabral NLA, Vale D, Lyra CO, Lima KC. Prevalência de desnutrição em idosos institucionalizados: uma revisão crítica sistemática. J Health Biol Sci. 2014;2(3):135-41.

2. Pereira MLAS, Moreira PA, Oliveira CC, Roriz AKC, Amaral MTR, Lima AL, et al. Nutritional status of institutionalized elderly Brazilians: a study with the Mini Nutritional Assessment. Nutr Hosp. 2015;31(3):1198-204. 
3. Senior HE, Henwood TR, Beller EM, Mitchell GK, Keogh JW. Prevalence and risk factors of sarcopenia among adults living innursing homes. Maturitas. 2015;82:418-23.

4. Silva SCM, Aires CN, Figueira YLV, Bogéa MRJ, Mendonça MJ. Alterações fisiológicas do idoso e seu impacto na ingestão alimentar: uma revisão de literatura. Rev Eletr Acervo Saúde. 2017;6:288-95.

5. Bell CL, Lee ASW, Tamura BK. Malnutrition in the nursing home. Curr Opin Clin Nutr Metab Care. 2015;18(1):17-23.

6. Brasil. Departamento de Informática do SUS. Estudo de estimativas populacionais por município, idade e sexo 2000-2015 - Brasil [Internet]. Rio de Janeiro: DATASUS; [2016?-] [acesso em 28 fev. 2018]. Disponível em: http://tabnet.datasus.gov.br/cgi/ deftohtm.exe?novapop/cnv/popbr.def

7. Brucki SMD, Nitrini R, Caramelli P, Bertolucci PHF, Okamoto IH. Sugestões para o uso do Mini-exame do Estado Mental no Brasil. Arq Neuro-psiquiatr. 2003;61(3B):777-81.

8. Rubenstein LZ, Harker JO, Salvà A, Guigoz Y, Vellas B. Screening for undernutrition in geriatric practice: developing the short-form mini-nutritional assessment (MNA-SF). J Gerontol Ser A Biol Sci Med Sci. 2001;56(6):366-72.

9. Chumlea WC, Roche AF, Steinbaugh ML. Estimating stature from knee height for persons 60 to 90 years of age. J Am Geriatr Soc. 1985;33(2):116-20.

10. Sociedad Internacional para el Avance de la Cineantropometría (ISAK). Normas Internacionales para la Valoración Antropométrica. [s.l.]: ISAK; 2001.

11. Aung KT, Zulkifli S. Nutritional status of institutionalized elderly. Sch J App Med Sci. 2016;4(10A):3608-11.
12. Vandewoude M, Van Gossum A. Nutritional screening strategy in nonagenarians: the value of the MNA-SF (Mini Nutritional Assessment Short Form) in nutriAction. J Nutr Health Aging. 2013;17(4):310-4.

13. Souza KT, Mesquita LAS, Pereira LA, Azeredo CM. Baixo peso e dependência funcional em idosos institucionalizados de Uberlândia (MG), Brasil. Ciência \& Saúde Coletiva 2014;19(8):3513-20.

14. Saka B, Ozkaya H, Karisik E, Akin S, Akpinar TS, Tufan F, et al. Malnutrition and sarcopenia are associated with increased mortality rate in nursing home residents: a prospective study. Eur Geriatr Med. 2013;7(3):232-8.

15. Serrano-Urreaa R, García-Meseguerb MJ. Relationships between nutritional screening and functionalimpairment in institutionalized Spanish older people. Maturitas. 2014;78:323-8.

16. Stange I, Poeschl K, Stehle P, Sieber CC, Volkert D. Screening for malnutrition in nursing home residents: comparison of different risk markers and their association to functional impairment. J Nutr Health Aging. 2013;17(4):357-63.

17. De Rouvray C, Jésus P, Guerchet M, Fayemendy P, Mouanga AM, Mbelesso P, et al. The nutritional status of older people with and without dementia living in an urban setting in central Africa: the EDAC study. J Nutr Health Aging. 2014;18(10):868-75.

18. Carlsson M, Haglin L, Rosendahl E, Gustafson Y. Poor nutritional status is associated with urinary tract infection among older people living in residential care facilities. J Nutr Health Aging. 2013;17(2):186-91.

19. Rambousková J, Slavíková M, Krsková A, Procházka B, Anděl M, Dlouhý P. Nutritional status assessment of institutionalized elderly in Prague, Czech Republic. Ann Nutr Metab. 2013;62(3):199-204. 